\title{
Eleições 2010: análise financeira de campanhas eleitorais
}

\author{
Carlos Henrique Rocha* \\ José Carlos Cavalcanti**
}

RESUMO - O principal objetivo deste trabalho é apresentar um breve exercício de economia financeira para demonstrar qual deveria ser a remuneração dos senadores eleitos dos estados de Minas Gerais, Rio de Janeiro, São Paulo e do Distrito Federal em 2010, se o financiamento de suas campanhas tivesse de ser devolvido aos patrocinadores por meio da renda do trabalho no Senado Federal. O trabalho faz, ainda, algumas considerações sobre o financiamento de campanhas políticas, para em seguida apresentar o exercício financeiro, utilizando dados do Tribunal Superior Eleitoral.

Palavras-chave: Eleições brasileiras de 2010. Financiamento de campanha eleitoral. Renda do trabalho do Senador da República.

\section{O FINANCIAMENTO DE CAMPANHAS POLÍTICAS}

A atividade de financiamento de campanhas políticas se refere ao levantamento de recursos (e sua aplicação) que as campanhas políticas fazem em épocas de eleição. Como as campanhas políticas têm muitas despesas, que vão desde os custos de viagens para os candidatos até a produção de propagandas na mídia, os candidatos despendem grande parte do seu tempo e esforço levantando recursos para o financiamento de suas campanhas.

O estudo das campanhas políticas é um assunto afeto às Ciências Políticas. Como apontado na rede social Wikipedia, apesar da literatura neste campo indicar que a maioria dos contribuintes de campanhas doa recursos para dar suporte aos candidatos com quem eles já têm afinidade ${ }^{1}$, há uma ampla percepção pública de que os doadores de campanhas esperam determinados "favores" em troca, tais como legislação específica sendo criada ou abolida (GILL e LIPSMEYER, 2005). Estas visões têm levado a calorosas discussões sobre a forma sobre como as campanhas políticas devem ser conduzidas, e, a mais recorrente, é se elas devem receber financiamento privado ou público.

Em alguns países, as campanhas eleitorais dependem fortemente de doadores privados. Em países como os Estados Unidos (EUA), por exemplo, o levantamento de recursos é frequentemente uma atividade significativa para o staff da campanha e para o candidato, especial* Doutor em teoria econômica pela Universidade de Liverpool. É professor da Universidade de Brasília. Endereço eletrônico: chrocha@unb.br.

${ }^{* *}$ Doutor em história econômica pela Universidade de Manchester. É professor na Universidade Federal de Pernambuco. Endereço eletrônico: jc-cavalcanti@decon.ufpe.br.

1 http://web.mit.edu/polisci/research/representation/CF_JEP_Final.pdf. 
mente nas campanhas mais proeminentes. Outros países escolhem usar fundos governamentais para conduzir as campanhas. O financiamento com orçamento público é amplamente utilizado em países da América do Sul e da Europa (SMILOV; TOPLAK, 2007). Os mecanismos para esse tipo de financiamento são variados, indo desde subsídios diretos a partidos políticos, passando por certos tipos de doações privadas aprovadas por governos, até isenções de impostos.

No Brasil já existe o fundo partidário, no entanto, o valor destinado a este fundo representa, quase sempre, uma pequena parcela do valor total das campanhas políticas, sendo o restante complementado pelas contribuições dos membros dos partidos, bem como por doações de pessoas físicas e jurídicas.

De qualquer forma, há uma crescente preocupação com o papel de alavanca que o dinheiro tem na política, e a influência de grupos de interesse em políticas é vocalizada com incrível regularidade nos debates populares e de políticas públicas. Muitas destas preocupações não encontram suporte na literatura empírica sobre contribuições para campanhas (CHAMON; KAPLAN, 2007). Enquanto existe uma ampla percepção popular de que a política envolve muito dinheiro, pesquisadores têm lutado em racionalizar porque há tão pouco dinheiro nas campanhas relativamente ao valor dos favores que aos contribuintes são alegados comprarem.

Chamon e Kaplan (2007) apontam que a indústria do açúcar nos EUA é uma excelente ilustração deste ponto. O programa de açúcar provê subsídios e grandes proteções tarifárias e não-tarifárias aos produtores americanos. O General Accounting Office dos EUA estima que o programa de açúcar, em 1998, proporcionou a conquista de um ganho líquido de mais de um bilhão de dólares para essa indústria. No entanto, as contribuições totais da indústria do açúcar naquele ciclo eleitoral foram de meros US $\$ 2,8$ milhões, menos de $0,3 \%$ do ganho líquido mencionado.

Ansolabehere Figueiredo e Snyder Jr. (2003) discutem um número de outros exemplos similares. Uma ilustração particularmente interessante é dada por Milyo, Primo e Groseclose (2000). Esses autores mostram que indústrias com reputação de render vasta influência política, tais como a indústria de compras militares, gastam várias vezes mais em filantropia que em campanhas eleitorais.

De qualquer forma, a literatura empírica tem tido sucesso misto em encontrar evidências sistemáticas que relacionam as contribuições de campanhas políticas com os resultados de políticas.

Por outra parte, Chamon e Kaplan (2007) tentam reconciliar a literatura empírica existente com a visão popular de que há muita influência de interesses especiais na política. Segundo eles, as contribuições de campanha têm tradicionalmente sido pensadas como uma 
transação envolvendo somente um contribuinte e o candidato recebedor, ou partido político recebedor. Tal perspectiva ignora largamente como a possibilidade de contribuir para um oponente poderia afetar os padrões de contribuições e suporte. Ao contrário da literatura anterior, eles permitem que grupos de interesse anunciem programas de contribuições que são condizentes não somente com a plataforma do candidato recebendo a oferta (o que eles chamam de contrato bilateral), mas também com a plataforma do candidato da oposição (o que eles denominam contrato multilateral). Como resultado, o candidato deve dar suporte a um interesse especial não somente de modo a receber uma contribuição, mas também de modo a desencorajar aquele interesse especial de fazer contribuição para o seu (ou sua) oponente. Isso equilibra o poder dos grupos de interesse, cuja influência pode ser dirigida, ou pelo menos alavancada, por implícitas contribuições fora do equilíbrio, gerando uma desconexão entre sua influência e as contribuições reais observadas.

\section{UM EXERCÍCIO USANDO A EVIDÊNCIA BRASILEIRA}

Muitas das questões acima levantadas mereceriam um tratamento mais aprofundado por parte dos pesquisadores brasileiros, afinal a economia dos mercados de campanhas políticas parece reproduzir as nuances de forças de mercados existentes em outros mais comumente analisados.

No entanto, um breve exercício de economia financeira pode ser aqui estabelecido na tentativa de considerar algumas questões que são habitualmente tratadas no âmbito popular, mas que, pelo que temos conhecimento, ainda não entraram nas análises empíricas mais formais dos economistas brasileiros.

O exercício procede da seguinte forma. Em 2010, as campanhas dos senadores eleitos em Minas Gerais (MG), no Rio de Janeiro (RJ), em São Paulo (SP) e no Distrito Federal (DF) somaram R $\$$ 63,3 milhões (dois senadores por estado e no Distrito Federal); quase R \$ 8,0 milhões por senador.

É sabido que tais recursos não saíram dos bolsos dos candidatos. Grande parte deles foi fornecida por patrocinadores. Por generosos patrocinadores.

Este artigo mostra por meio de números redondos que nenhum dos senadores eleitos de MG, do RJ, SP e do DF, receberá recursos do Senado Federal, na forma de salário, durante os próximos oito anos, suficientes para devolver a seus patrocinadores; eles esperam que sejam pagos como? Ou não esperam serem pagos? 


\section{ANÁLISE DOS DADOS}

Analisou-se o custo das campanhas eleitorais brasileiras em 2010 para o cargo de senador nos estados de Minas Gerais, do Rio de Janeiro, de São Paulo e no Distrito Federal. Foram consideradas as campanhas vencedoras nesses estados e no DF.

A Tabela 1 apresenta os senadores eleitos por unidade da federação, os seus respectivos partidos políticos e o valor aportado na campanha. O senador eleito Cristovam Buarque foi o mais votado no Distrito Federal, o senador eleito Aécio Neves foi o primeiro em Minas Gerais, e assim sucessivamente.

TABELA 1 - SENADORES ELEITOS EM 2010, SEGUNDO O ESTADO

\begin{tabular}{lr|r|r}
\hline \multicolumn{1}{c|}{ Senador Eleito } & Estado & $\begin{array}{c}\text { Partido } \\
\text { Político }\end{array}$ & \multicolumn{1}{c}{$\begin{array}{c}\text { Recursos } \\
\text { Aportados (R\$) }\end{array}$} \\
\hline Cristovam Ricardo Cavalcanti Buarque & DF & PDT & $2.073 .312,00$ \\
Rodrigo Sobral Rollemberg & DF & PSB & $1.312 .712,78$ \\
Aécio Neves da Cunha & MG & PSDB & $11.970 .313,79$ \\
Itamar Augusto Cautiero Franco & MG & PPS & $11.589 .868,48$ \\
Luiz Lindbergh Farias Filho & RJ & PT & $12.654 .169,53$ \\
Marcelo Bezerra Crivela & RJ & PRB & $2.656 .916,35$ \\
Aloysio Nunes Ferreira Filho & SP & PSDB & $9.193 .018,50$ \\
Marta Suplicy & SP & PT & $11.837 .330,74$ \\
\hline
\end{tabular}

FONTE: Tribunal Superior Eleitoral (2010).

Como pode ser visto, as campanhas relativamente mais modestas foram as dos senadores eleitos pelo Distrito Federal Rodrigo Sobral Rollemberg e Cristovam Buarque, respectivamente do PSB e do PDT. A campanha mais generosa foi a do senador eleito Luiz Lindbergh Farias Filho, do PT do Rio de Janeiro.

Um senador da república recebe por ano quinze salários, com mandato de oito anos; são cento e vinte salários por legislatura. Um funcionário da iniciativa privada recebe treze salários por ano; o professor universitário federal também.

Qual o valor atual do ganho de um senador durante a sua legislatura? Essa pergunta é facilmente respondida por meio da aplicação da seguinte fórmula (BRIGHAM e HOSTON, 1999):

$$
G_{s}=A\left[\frac{1}{r-g}-\frac{1}{r-g}\left(\frac{1+g}{1+r}\right)^{n}\right], r>g
$$

A Equação (1) retorna o valor atual de uma anuidade crescente A, neste caso, igual ao salário anual do senador, durante oito anos. Para encontrar o ganho atual de um senador durante a legislatura $G_{\mathrm{S}}$ é preciso definir os valores para: (a) A (anuidade), (b) g (taxa de crescimento de A), (c) r (taxa de desconto) e n (número de períodos). 
Já sabemos que n é igual a oito anos. A variável A é o valor corrente do salário anual de um senador da república, igual a $\mathrm{R} \$ 247.681,35$ (Portal da Transparência). Suponha agora que r seja igual a $10 \%$ ao ano e que g seja igual a $5 \%$ ao ano.

Estabelecidos os valores para as variáveis na equação (1), pode-se calcular o valor atual do ganho de um senador durante a sua legislatura $G_{s}$; igual a $R \$ 1.539 .369,96^{2}$. Noutras palavras, o ganho de um senador da república durante a sua legislatura, i.e., durante oito anos, é de aproximadamente um milhão e quinhentos e quarenta mil reais, avaliados hoje. Obviamente, o ganho é insuficiente para cobrir o aporte feito pelos patrocinadores dos senadores eleitos nos estados de MG, RJ, SP e no Distrito Federal.

TABELA 2 - DIFERENÇA ENTRE SALÁRIO DO SENADOR E APORTE DE CAMPANHA, 2010

\begin{tabular}{lr}
\multicolumn{1}{c}{ Senador Eleito } & \multicolumn{1}{c}{ Superávit/Déficit (R\$) } \\
\hline Cristovam Ricardo Cavalcanti Buarque & $-533.942,04$ \\
Rodrigo Sobral Rollemberg & $226.657,18$ \\
Aécio Neves da Cunha & $-10.430 .943,83$ \\
Itamar Augusto Cautiero Franco & $-10.050 .498,52$ \\
Luiz Lindbergh Farias Filho & $-11.114 .799,57$ \\
Marcelo Bezerra Crivela & $-1.117 .546,39$ \\
Aloysio Nunes Ferreira Filho & $-7.653 .648,54$ \\
Marta Suplicy & $-10.297 .960,78$ \\
\hline
\end{tabular}

A segunda coluna da Tabela 2 é a diferença entre o valor atual do ganho do senador durante a sua legislatura $(\mathrm{R} \$ 1.539 .369,96)$ e o valor aportado na respectiva campanha (Tabela 1). Como se pode constatar, somente o senador eleito do DF, Rodrigo Rollemberg, teria capacidade de pagar aos patrocinadores de suas campanhas com o rendimento de seu trabalho.

Se o único rendimento do senador fosse o salário do trabalho, então, pode-se concluir que o senador eleito Rodrigo Rollemberg passaria a viver durante oito anos com um salário mensal de aproximadamente $\mathrm{R} \$ 2,0$ mil, considerando que ele devolva os recursos de campanha aos seus patrocinadores.

\section{4 ÚLTIMAS CONSIDERAÇÕES}

Este artigo mostrou alguns aspectos importantes do financiamento de campanhas políticas, e de modo particular, que os salários dos senadores eleitos de três estados brasileiros, a serem recebidos durante a legislatura 2011-2018, são insuficientes para devolver os recursos aportados por seus patrocinadores em suas campanhas. Em alguns casos, o déficit chega a mais $\mathrm{R} \$ 10$ milhões.

Como os patrocinadores esperam serem pagos? Eles esperam mesmo que sejam pa-

2 É importante dizer que este valor depende dos parâmetros adotados na equação (1). Se, por exemplo, a taxa de crescimento do salário anual do senador for de $8 \%$, ceteris paribus, então, $G_{\mathrm{S}}=\mathrm{R} \$ 1.690 .764,50$. 
gos? Precisa-se investigar!

\section{REFERÊNCIAS}

ANSOLABEHERE, S.; FIGUEIREDO, J.; SNYDER Jr., J. Why is there so little money in U.S. politics? Journal of Economic Perspectives, v. 17, n. 1, p. 105-130, 2003.

BRIGHAM, E. F.; HOUSTON, J. F. Fundamentos da moderna administração financeira. Rio de Janeiro: Campus, 1999.

CHAMON, M.; KAPLAN, E. The iceberg theory of campaign contributions: political threats and interest group behavior, mar., 2007. Disponível em: < http://www.iq.harvard.edu/files/ iqss/old/PPE/kaplan.pdf.>.

GILL, D.; LIPSMEYER, C. Soft money and hard choices: why political parties might legislate against soft money donations? Public Choice, v. 123, n. 3-4, p. 411-38, 2005.

SMILOV, D.; TOPLAK, J. (eds.) Political finance and corruption in Eastern Europe. Ashgate Press, 2007.

MILYO, J.; PRIMO, D.; GROSECLOSE, T. Corporate PAC campgain and contributions in persepctive. Business and Politics, v. 2, n. 1, p. 75-88, 2000. 